\title{
Metode dan Prosedur Penerjemahan Quote Anime Bahasa Jepang ke dalam Bahasa Indonesia pada Official Akun LINE Bahasa Jepang Bersama
}

\author{
Ida Ayu Made Dwi Ratna Komala*, Made Ratna Dian Aryani, Renny Anggraeny \\ Program Studi Sastra Jepang Fakultas Ilmu Budaya \\ [dayuratna76@gmail.com] \\ *Corresponding Author
}

\begin{abstract}
The title of this research is "Method and Procedure of Translation used in Anime Quotes from Japanese to Indonesia at Official Account LINE Bahasa Jepang Bersama". The purpose of the research is to identify the types of technique, procedure, and method of translation applied in translating anime quotes. Theories used in this research are the theory of translation techniques proposed by Molina and Albir (2002), the procedure of translation by Vinay and Darbelnet (1995), and the translation methods by Newmark (1988). The research data was analyzed by translational equivalence method and glossing. The result of the data analysis indicates that there are several translation techniques applied, they are literal translation, amplification, modulation, linguistic amplification,established equivalence, reduction, and transposition. The most found translation technique is literal translation because its aim is to produce a translation that stick to the originality of the language source text content and form. Then, there are procedures of translation applied, they are literal translation, transposition, and modulation. Thereafter for the method of translation applied they are literal translation, free translation, communicative translation, and idiomatic translation. The most found translation method is free translation because its aim is to produce a translation that fit to the need of target language readers. The translation methods applied tend to be oriented towards the target language.
\end{abstract}

Keywords: quote, procedure of translation, translation method

\begin{abstract}
Abstrak
Penelitian ini berjudul "Metode dan Prosedur Penerjemahan Quote Anime bahasa Jepang ke dalam bahasa Indonesia pada Official Akun LINE bahasa Jepang bersama". Penelitian ini bertujuan untuk mengetahui jenis teknik, prosedur dan metode penerjemahan yang diterapkan dalam menerjemahkan quote anime. Teori yang digunakan pada penelitian ini adalah teori teknik penerjemahan dari Molina dan Albir (2002), prosedur penerjemahan dari Vinay dan Darbelnet (1995) dan metode penerjemahan dari Newmark (1988). Data penelitian ini dianalisis dengan metode padan translasional dan teknik glossing. Hasil analisis data menunjukkan bahwa terdapat beberapa teknik penerjemahan yang diterapkan, yaitu teknik harfiah, teknik amplifikasi, teknik modulasi, teknik amplifikasi linguistik, teknik padanan lazim, teknik reduksi dan teknik transposisi. Teknik penerjemahan harfiah paling banyak ditemukan karena bertujuan untuk menghasilkan terjemahan yang
\end{abstract}


masih mempertahankan keaslian isi dan bentuk dari teks BSu. Selanjutnya pada bagian prosedur penerjemahan terdapat beberapa prosedur penerjemahan yang diterapkan, yaitu prosedur harfiah, prosedur transposisi dan prosedur modulasi. Selanjutnya metode penerjemahan yang diterapkan yaitu, metode harfiah, metode penerjemahan bebas, metode komunikatif dan metode idiomatik. Metode penerjemahan bebas paling banyak ditemukan karena bertujuan untuk menghasilkan terjemahan yang sesuai dengan kebutuhan pembaca BSa. Metode penerjemahan yang diterapkan cenderung berorientasi pada BSa.

Kata Kunci: quote, prosedur penerjemahan, metode penerjemahan

\section{Latar Belakang}

Zaman era pertengahan tahun 1990an penayangan anime Jepang di Indonesia mendapat respon positif dari masyarakat hingga sekarang penggemar anime Jepang di Indonesia semakin meningkat. Saat menonton anime biasanya orang-orang tidak hanya tertarik dengan jalan ceritanya saja namun banyak hal yang dapat dipelajari dari menonton anime salah satunya yaitu quote-quote yang diucapkan oleh para tokoh yang ada dalam anime tersebut. Menurut Trench (1884), quote adalah sebuah kata-kata, frasa yang diulang persis atau disalin dari sebuah teks maupun dari kata-kata seseorang yang dikutip kembali. Quote bisa berupa sebuah kalimat yang dapat memberikan motivasi maupun solusi serta mengandung makna yang inspiratif, dan biasanya muncul dari gagasan seorang pengarang, atau dari ucapan orang terkenal karena keahliannya seperti tokoh, pejabat, ilmuwan, dan motivator. Quote sering diambil dari sebuah buku, film, dan novel selain itu quote juga sering ditemukan di dalam media sosial internet baik itu yang membahas tentang anime maupun media sosial secara umum. Selain media sosial internet yang membahas tentang anime terdapat pula situs media sosial berbasis pendidikan yang memposting quote-quote anime untuk menarik minat pembelajar bahasa Jepang agar lebih mendalami bahasa Jepang sehingga perlu adanya penerjemahan dari quote anime tersebut. Seorang penerjemah ketika ingin menghasilkan hasil terjemahan yang baik dan benar harus terlebih dahulu menentukan teknik penerjemahan yang akan diterapkan khususnya dalam menerjemahkan quote anime. Metode dan prosedur yang digunakan oleh penerjemah juga sangat berpengaruh terhadap kualitas serta aspek keberterimaan dari hasil terjemahan itu sendiri. Oleh karena itu untuk mendapatkan hasil penelitian yang lebih mendetail dari penelitian yang sudah pernah dilakukan sebelumnya maka dalam penelitian ini selain berfokus pada masalah metode dan prosedur penerjemahan juga menambahkan teknik penerjemahan ke dalam rumusan masalah. Pemilihan topik penelitian ini dikarenakan objek kajian yang diteliti merupakan hal yang menarik yaitu penerjemahan quote-quote anime yang terdapat dalam official akun LINE dan diambil dari berbagai judul anime yang cukup terkenal dikalangan para pecinta anime. Penelitian serupa dengan penelitian ini sudah pernah dilakukan sebelumnya, diantaranya yaitu penelitian dari Pratama (2016), Jong (2016) dan Aryani (2018), namun dengan sumber data dan rumusan masalah yang berbeda.

\section{Pokok Permasalahan}

Berdasarkan latar belakang yang telah dipaparkan, maka rumusan masalah yang dianalisis dalam penelitian ini dapat dirumuskan sebagai berikut:

a. Bagaimanakah teknik penerjemahan yang diterapkan dalam menerjemahkan quote anime bahasa 
Jepang dengan terjemahannya pada official akun LINE bahasa Jepang bersama?

b. Bagaimanakah prosedur penerjemahan yang diterapkan dalam menerjemahkan quote anime bahasa Jepang dengan terjemahannya pada official akun LINE bahasa Jepang bersama?

c. Bagaimanakah metode penerjemahan yang diterapkan dalam menerjemahkan quote anime bahasa Jepang dengan terjemahannya pada official akun LINE bahasa Jepang bersama?

\section{Tujuan Penelitian}

Penelitian ini bertujuan untuk menambah wawasan para pembaca khususnya dalam bidang penerjemahan di media eletronik yaitu salah satunya yang terdapat dalam media sosial LINE. Secara khusus penelitian ini bertujuan untuk mengetahui teknik, prosedur dan metode penerjemahan yang digunakan dalam menerjemahkan quote anime dalam official akun LINE bahasa Jepang bersama.

\section{Metode Penelitian}

Pengumpulan data dalam penelitian ini dilakukan dengan metode simak dengan teknik catat. Tahap analisis data digunakan metode padan translasional dan teknik glossing. Penyajian hasil analisis digunakan metode informal dengan dipaparkan menggunakan katakata biasa. Teori yang digunakan dalam penganalisisan data, yaitu teori teknik penerjemahan yang dikemukakan oleh Molina dan Albir (2002) untuk mengetahui teknik penerjemahan yang diterapkan dalam menerjemahkan quote anime, teori prosedur penerjemahan yang dikemukakan oleh Vinay dan Darbelnet (1995) untuk mengetahui prosedur penerjemahan yang diterapkan dalam menerjemahkan quote anime, serta teori metode penerjemahan oleh Newmark
(1988) untuk mengetahui metode penerjemahan yang diterapkan dalam menerjemahkan quote anime dalam official akun LINE bahasa Jepang bersama.

\section{Hasil dan Pembahasan}

Quote anime berbahasa Jepang yang diterjemahkan ke dalam bahasa Indonesia pada official akun LINE bahasa Jepang bersama ditemukan tujuh jenis teknik penerjemahan, tiga jenis prosedur penerjemahan, dan empat jenis metode penerjemahan yang diterapkan. Berikut pemaparan terhadap analisis quote anime tersebut.

\subsection{Teknik Penerjemahan Harfiah}

(1) TSu : 人間 は 恋 と 革命
ningen wa koi to kakume
manusia TOP cinta dan revolusi
の ために 生まれてきた
no tameni umaretekita
GEN untuk dilahirkan-B.LMP
の だ
SHU KOP

TSa : 'Manusia itu terlahir untuk cinta dan revolusi' ( Azumi Koutaro anime :Tsuki Ga Kirei) Official akun LINE BJB, 23 Desember 2017

Berdasarkan paparan data (1), dapat terlihat bahwa tidak terdapat ungkapan yang berbeda pada TSa, hasil terjemahan kalimat quote ini diterjemahkan secara harfiah dan disesuaikan dengan sistem gramatikal $\mathrm{BSa}$. Pesan yang ingin disampaikan dari kalimat quote ini adalah, setiap manusia yang dilahirkan di dunia ini diharapkan untuk menjadi manusia yang penuh cinta dan kasih sayang terhadap sesama makhluk di bumi ini selain itu setiap manusia yang dilahirkan diharapkan dapat membawa perubahan untuk dunia ini tentunya perubahan yang lebih baik. Prosedur yang digunakan adalah prosedur harfiah begitupula 
dengan metode penerjemahan yang digunakan yaitu metode penerjemahan harfiah dengan hasil terjemahan yang cenderung berorientasi ke BSu.

\subsection{Teknik Transposisi}

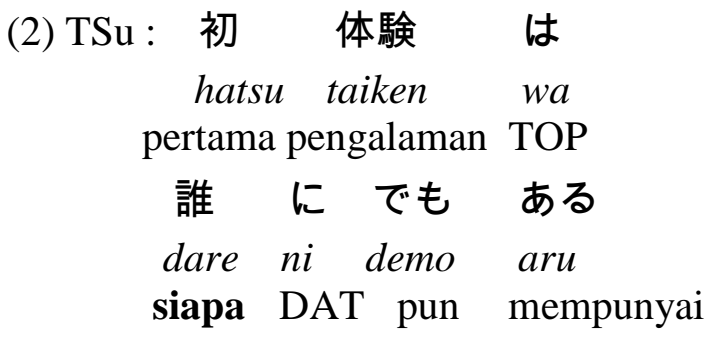

TSa : 'Semua orang memiliki pengalaman pertama.'

( Gowther anime : Nanatsu no Taizai) Official akun LINE BJB,

13 Maret 2018

Berdasarkan paparan data (2), kata 'dare' merupakan kata yang termasuk dalam kelas kata pronomina yang memiliki arti 'siapa, seseorang' namun pada TSa kata 'dare' tersebut diterjemahkan menjadi 'semua' dan kata 'semua' itu termasuk dalam kelas kata numeralia. Jadi dapat dilihat bahwa dalam proses penerjemahan quote ini telah terjadi penggantian dan penurunan kelas kata pada kata 'dare' yaitu dari kelas kata pronomina menjadi kelas kata numeralia menjadi 'semua' pada TSa. Pesan yang terkandung dalam quote anime ini adalah, setiap orang pasti memiliki pengalaman pertama dalam hidupnya baik itu pengalaman pertama yang menyenangkan maupun sebaliknya karena dari pengalaman pertamalah kita bisa belajar untuk menjalani kehidupan selanjutnya. Prosedur penerjemahan yang digunakan juga merupakan prosedur transposisi yaitu prosedur yang mengganti kelas kata 'dare' menjadi 'siapa' pada proses penerjemahan quote anime, sedangkan metode yang digunakan adalah metode harfiah karena tidak ditemukan adanya pergeseran makna maupun perbedaan hasil terjemahan antara TSu dan TSa.

\subsection{Teknik Modulasi}

(3) $\mathrm{TSu}$ : 失敗 は 成功 の 源 shippai wa seiko no minamoto kegagalan TOP sukses GEN sumber

TSa : 'Kegagalan adalah awal dari kesuksesan'

( Koro sensei anime:Ansatsu Kyoushitsu) Official akun LINE BJB,

28 Agustus 2017

Berdasarkan paparan data (3), terdapat kata 'minamoto' yang dalam bahasa Jepang jika diartikan ke dalam bahasa Indonesia memiliki arti 'sumber, asal' sedangkan pada TSa kata 'minamoto' diterjemahkan menjadi 'awal' yang mana jika dalam bahasa Jepang dapat diartikan dengan 'hajime' atau yang lainnya. Penerjemahan kata tersebut, menyebabkan terjadinya pergeseran sudut pandang makna yang ada pada TSu ke dalam hasil terjemahan TSa. Penerjemah lebih memilih menggunakan kata 'awal' daripada kata 'sumber' karena penerjemah ingin membuat hasil terjemahan yang lebih halus, tidak kaku dan terpaku pada BSu namun tetap tidak mengurangi pesan yang terdapat pada TSu. Pesan yang terkandung dalam quote anime ini adalah, setiap kita mengalami kegagalan dalam suatu usaha yang kita ingin capai janganlah langsung menyerah begitu saja karena disetiap kita mengalami kegagalan pasti ada kesempatan lain yang bisa kita dapatkan untuk mencapai kesuksesan, jika gagal berusahalah bangkit lagi dan jalani setiap prosesnya. Prosedur yang dipilih oleh penerjemah adalah prosedur modulasi yaitu prosedur penerjemahan yang juga mempunyai kesesuaian teori dengan teknik modulasi yaitu adanya upaya dalam proses penerjemahan yang menghasilkan perubahan sudut pandang 
makna. Selanjutnya metode penerjemahan yang digunakan adalah metode komunikatif yaitu metode yang mengupayakan menerjemahkan makna kontekstual pada kata 'minamoto' dalam TSu diterjemahkan menjadi kata 'awal' dalam TSa. Hal tersebut dilakukan oleh penerjemah bertujuan untuk menyesuaikan aspek kebahasaan yang ada pada TSa.

\subsection{Teknik Amplifikasi}

(4) TSu：人は 何か の 犠牲

hito wa nanika no gisei

orang TOP sesuatu GEN pengor- banan

$\begin{array}{llll}\text { 無し に } & \text { は } & \text { 何 } & \text { も } \\ \text { nashi ni } & \text { wa } & \text { nani } & \text { mo } \\ \text { tidak DAT } & \text { TOP apa } & \text { pun }\end{array}$

得ることは 出来ない

eru koto wa dekinai

mendapat sesuatu TOP tidak bisa- B.NEG

TSa : Seseorang yang menjalani hidupnya tanpa melakukan pengorbanan tidak akan memperoleh apapun.

( Edward Elric anime: Fullmetal Alchemist)

Official akun LINE

BJB, 16 Agustus 2017

Berdasarkan paparan data (4), dapat dilihat bahwa ada perbedaan penerjemahan yang terjadi antara TSu dan TSa, perbedaan ini terlihat dari adanya penambahan ungkapan 'menjalani hidupnya' yang terdapat pada TSa, dengan menambahkan informasi tersebut penerjemah ingin menunjukkan pernyataan tokoh anime yang mengungkapkan quote tersebut secara lebih jelas dan berterima dalam BSa namun tidak mengubah ataupun mengurangi isi pesan yang terkandung dalam quote anime tersebut. Makna ataupun pesan yang ingin disampaikan dari quote anime ini adalah, bahwa dalam hidup ini kita sebagai manusia pasti ingin mencapai banyak hal dalam kehidupan ini, namun dengan segala kekurangan yang kita miliki tidak semua hal itu bisa kita capai, salah satu contohnya yaitu, setiap orang pasti ingin sukses dalam karir dan untuk mencapai itu, banyak hal yang harus dikorbankan misalnya waktu, masa muda dan lain sebagainya. Untuk mencapai sukses dalam karir kita tidak mungkin bisa berleha-leha menghabiskan masa muda kita, pastinya waktu tersebut kita gunakan untuk belajar dan bekerja keras demi meningkatkan karir. Metode penerjemahan yang dipilih oleh penerjemah adalah metode bebas yang lebih mengutamakan isi yang terkandung pada BSa dengan menghasilkan terjemahan yang berupa parafrase yang lebih panjang dari TSu dilihat dari adanya penambahan penjelasan yaitu berupa ungkapan 'menjalani hidupnya' pada TSa.

\subsection{Teknik Amplifikasi Linguistik}

(5) TSu : 恥べき は 弱い

hazubeki wa yowai memalukan TOP lemah

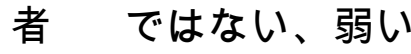

mono dewanai, yowai orang B.NEG lemah

まま の 者 だ

terus-menerus GEN orang KOP

TSa : 'menjadi lemah bukanlah hal yang memalukan, yang memalukan adalah jika terus-terusan lemah'

\section{( Fuegeoleon anime : Black Cover) \\ Official akun LINE BJB, \\ 18 Maret 2018}

Berdasarkan paparan data (5), terdapat adanya perbedaan antara TSu dan TSa, terlihat dari adanya penambahan kata kerja 'menjadi' penambahan unsur linguistik berupa kata kerja 'menjadi' tersebut bertujuan untuk 
memperjelas pernyataan yang ada pada TSa yang tidak dirumuskan pada TSu. Pesan yang terkandung dalam quote ini adalah, sebagai manusia biasa ada saatnya ketika kita menjadi lemah, tak berdaya karena suatu peristiwa buruk telah terjadi ataupun karena cita-cita maupun impian yang kita inginkan tidak tercapai, wajar saja ketika hal itu terjadi kita merasa putus asa, lemah tak berdaya tetapi keadaaan tersebut tidak boleh sampai berlarut-larut dan membiarkan jiwa kita menjadi lemah karena walau bagaimanapun kita tetap harus bangkit dan semangat untuk menjalani kehidupan di masa mendatang. Metode yang digunakan dalam proses penerjemahan quote ini adalah metode penerjemahan bebas dilihat dari adanya penambahan kata kerja 'menjadi' pada TSa yang merupakan suatu upaya penerjemah yang lebih mengutamakan isi teks terjemahan agar mudah dipahami oleh pembaca sasaran tanpa memperhatikan bentuk asli dari TSu.

\subsection{Teknik Reduksi}

(6) $\mathrm{TSu}$ ：奇跡 は 諦めない

Kiseki wa akiramenai

keajaiban TOP tidak menyerah

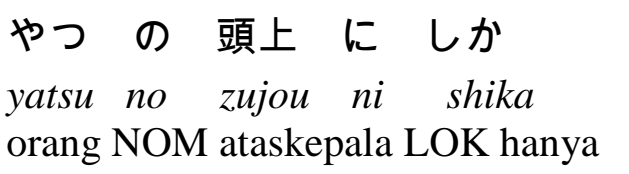

\section{降りてこない! “奇跡}

oritekonai!! "kiseki tidak turun-

B.NEG keajaiban

$$
\begin{array}{ll}
\text { を } & \text { ナメンじゃねえー! } \\
o & \text { namenjanee-! }
\end{array}
$$

AK jangan menyepelekan

TSa : 'Keajaiban hanya akan terjadi pada orang-orang yang tidak menyerah! "Jangan remehkan keajaiban'!!!

$$
\begin{array}{r}
\text { ( Ivankov anime : One Piece) } \\
\text { Official akun LINE BJB, } \\
2 \text { Desember } 2018
\end{array}
$$

Berdasarkan paparan data (6), dapat terlihat bahwa adanya pengurangan informasi maupun ungkapan yang terjadi antara TSu dan TSa, hal ini terbukti dengan tidak diterjemahkannya kalimat 'zujou ni shika oritekonai !!' yang secara harfiah memiliki arti 'tidak turun hanya di atas kepala'. Penerjemah tidak menerjemahkan kalimat tersebut ke dalam TSa, karena pesan maupun informasi yang ada pada TSu sudah dapat tersampaikan dengan baik tanpa menerjemahkan kalimat tersebut jadi ada atau tidaknya kalimat itu dalam TSa tidak memiliki pengaruh yang cukup besar pada hasil terjemahan quote tersebut secara keseluruhan. Pesan yang terkandung dalam quote anime ini adalah, suatu keajaiban itu sesungguhnya pasti bisa saja terjadi jika kita terus berusaha keras untuk mewujudkan keajaiban yang kita inginkan karena sesungguhnya keajaiban itu bukanlah hal yang mustahil, keajaiban sama dengan hasil dari suatu proses dan usaha kerja keras kita yang pantang menyerah. Metode yang digunakan dalam menerjemahkan quote ini adalah metode penerjemahan bebas, dapat terlihat dari adanya pengurangan pada TSa karena terdapat kalimat yang tidak diterjemahkan untuk menghasilkan terjemahan yang berterima dalam BSa.

\subsection{Teknik Padanan Lazim}

(7) TSu : 神樣 は 私たち

$\begin{array}{lll}\text { Kamisama } & \text { wa } & \text { watashitachi } \\ \text { Tuhan TOP } & \text { kita }\end{array}$

に 堪える こと の

ni taeru koto no

DAT tahan hal GEN

出来ない苦しみ は

dekinai kurushimi wa

tidak bisa penderitaan TOP

与えにならない

tidak memberi-B.NEG

TSa : 'Tuhan tidak akan memberi kita

cobaan yang tidak bisa kita hadapi'. 
( Konno Yuuki anime : Sword Art

Online)

Official akun LINE BJB,

18 Oktober 2017

Berdasarkan paparan data (7), dapat terlihat adanya perbedaan ungkapan yang terdapat pada TSu dan TSa, yaitu pada ungkapan 'kurushimi, yang secara harfiah memiliki arti 'penderitaan, kesusahan, kesengsaraan' namun pada TSa penerjemah mengubahnya menjadi ungkapan 'cobaan' dan itu lebih terdengar lazim digunakan pada TSa. Alasan yang mendasari ungkapan ini lebih lazim digunakan, karena menurut Sunendar dkk (2016) ungkapan 'cobaan' memiliki arti 'sesuatu yang dipakai untuk menguji (ketabahan, iman dan sebagainya) yang diterima dari Tuhan' sedangkan ungkapan 'penderitaan' memiliki arti 'keadaan yang menyedihkan yang harus ditanggung' oleh karena itu jelas terlihat bahwa ungkapan 'cobaan' lebih sesuai dan lazim digunakan dalam BSa jika penderitaan yang berhubungan dengan takdir Tuhan. Metode digunakan oleh penerjemah dalam menerjemahkan kalimat quote ini adalah metode idiomatik karena dalam menerjemahkan TSu penerjemah berupaya menghasilkan makna dengan kesan yang lebih lazim dan akrab digunakan pada BSa yaitu dengan memilih menggunakan kata 'cobaan' pada TSa untuk merepresentasikankata 'kurushimi' pada TSu yang dalam hal ini kata 'cobaan' tidak ditemukan pada teks aslinya namun memiliki kesepadanan makna dengan arti kata 'kurushimi' pada BSu.

\section{Simpulan}

Berdasarkan analisis yang telah dilakukan pada quote-quote anime berbahasa Jepang beserta terjemahannya yang berbahasa Indonesia, ditemukan sebanyak tujuh buah teknik penerjemahan yang diterapkan dalam menerjemahkan quote anime. Ketujuh kategori teknik penerjemahan tersebut, terdiri dari : teknik harfiah, teknik amplifikasi, teknik modulasi, teknik amplifikasi linguistik, teknik padanan lazim, teknik transposisi, dan yang terakhir adalah teknik reduksi.

Selanjutnya pada bagian prosedur penerjemahan setelah dilakukan analisis data secara keseluruhan, bahwa dapat disimpulkan dalam penerjemahan quote anime ini penerjemah hanya menggunakan beberapa dari kategori prosedur penerjemahan yaitu meliputi : prosedur harfiah, prosedur modulasi, dan prosedur transposisi. Ditemukan sebanyak dua kelompok haluan metode penerjemahan dalam penelitian ini yaitu, metode harfiah yang berorientasi pada Bsu serta metode penerjemahan bebas, metode idiomatik, dan metode komunikatif yang berorientasi pada BSa. Kelompok yang berorientasi pada $\mathrm{BSu}$ terdiri dari penggabungan penggunaan teknik harfiah, prosedur harfiah, teknik transposisi dan prosedur transposisi ditemukan sebanyak 10 data. Sedangkan kelompok yang berorientasi pada Bsa yaitu, teknik amplifikasi 6 data, teknik reduksi 1 data, teknik padanan lazim 1 data, teknik modulasi 7 data, teknik amplifikasi linguistik 2 data yang seluruhnya berjumlah 17 data. Berdasarkan pemaparan dari kuantitas data tersebut, dapat diketahui bahwa metode penerjemahan yang diterapkan oleh penerjemah dalam menerjemahkan quote anime ini lebih cenderung berorientasi pada $\mathrm{BSa}$.

\section{Daftar Pustaka}

Aryani, MRD. 2018. "Tehnique and Translation Methods of Isshunboshi Tales into Indonesian" $\left(2^{\text {nd }}\right.$ Internasional Conference on Japanese Language Education, Literature and Culture). Bandung. 
Universitas Pendidikan Bandung.

Vol.2.P.83-86

Jong, Hwayeon. 2016. "Prosedur dan Metode Penerjemahan Lirik Lagu dalam Film Frozen" (Skripsi). Denpasar : Universitas Udayana.

Molina, L \& Albir, A.H.2002. Translation Technique Revisited : A Dynamic and Fungsionalist Approach. Barcelona : Universitas Autonoma de Barcelona

Newmark, Peter. 1988. A Textbook of Translation. UK: Prentice Hall

Pratama, Putu Sarhita Cindra, Maria Gorethy Nie Nie, and I. Gede Oeinada. 2016 "Teknik Dan Metode Penerjemahan Kata-Kata Bijak (Meigen No Kotoba) Dalam Komik Naruto Volume 41-60 Karya Masashi Kishimoto."

Sunendar,Dadang,dkk.2016. Kamus Besar Bahasa Indonesia (Edisi Kelima). Jakarta : Pengembang KBBI Daring

Trench, Richard Chenevik, dkk. 1884. Oxford English Dictionary (First Edition). United Kingdom : Oxford University Press

Vinay, Jean Paul and Darbelnet, Jean. 1995. Comparative Stylistics of French and English A Methodology of Translation. Amsterdam. The Netherlands: John Benjamins Publishing Company 